\title{
How Does Acetylcholine Lose Trimethylamine? A Density Functional Theory Study of Four Competing Mechanisms*
}

\author{
Hadi Lioe, ${ }^{\mathrm{a}, \mathrm{b}}$ Christopher K. Barlow, ${ }^{\mathrm{a}, \mathrm{b}, \mathrm{c}}$ and Richard A. J. O'Hair ${ }^{\mathrm{a}, \mathrm{b}, \mathrm{c}}$ \\ a School of Chemistry, University of Melbourne, Victoria, Australia \\ ${ }^{\mathrm{b}}$ Bio21 Institute of Molecular Science and Biotechnology, University of Melbourne, Victoria, Australia \\ ${ }^{c}$ Australian Research Council Centre of Excellence for Free Radical Chemistry and Biotechnology, University \\ of Melbourne, Victoria, Australia
}

Low-energy collision-induced dissociation (CID) of acetylcholine (ACh) yields only two fragment ions: the dominant $\mathrm{C}_{4} \mathrm{H}_{7} \mathrm{O}_{2}{ }^{+}$ion at $m / z$ 87, arising from trimethylamine loss; and protonated trimethylamine at $\mathrm{m} / \mathrm{z} 60$. Since the literature is replete with conflicting mechanisms for the loss of trimethylamine from ACh, in this article density functional theory (DFT) calculations are used to assess four competing mechanisms: (1) Path A involves a neighboring group attack to form a five-membered ring product, 2-methyl-1,3-dioxolan-2-ylium cation; (2) Path $\mathrm{B}$ is a neighboring group attack to form a three-membered ring product, 1-methyloxiranium ion; (3) Path $\mathrm{C}$ involves an intramolecular elimination reaction to form $\mathrm{C}=\mathrm{O}$ protonated vinylacetate; and (4) Path $\mathrm{D}$ is a 1,2-hydride migration reaction forming $\mathrm{CH}_{2}-$ protonated vinylacetate. At the MP2/6-311++G(2d,p)//B3-LYP/6-31+G $(d, p)$ level of theory path A is the kinetically favored pathway, with a transition-state energy barrier of $37.7 \mathrm{kcal}$ $\mathrm{mol}^{-1}$ relative to the most stable conformer of ACh. The lowest energy pathway for the formation of protonated trimethylamine was also calculated to proceed via path A, involving proton transfer within the ion-molecule complex intermediate, with the exocylic methyl group being the proton donor. To confirm the site of proton transfer, low-energy CID of acetyl- $d_{3}$-choline $\left(d_{3}-\mathrm{ACh}\right)$ was carried out, which revealed loss of trimethylamine and the formation of $\mathrm{Me}_{3} \mathrm{ND}^{+}$. (J Am Soc Mass Spectrom 2009, 20, 238-246) (C) 2009 Published by Elsevier Inc. on behalf of American Society for Mass Spectrometry

A though there is renewed interest in smallmolecule analysis via mass spectrometry (MS) based methods in areas such as metabolomics, a general appreciation of fragmentation mechanisms appears to have lagged behind. Indeed many recent studies have proposed mechanisms without a consideration of past work or without the use of well-established methods (such as isotopic labeling or theoretical modeling), prompting a recent editorial [1]. A prime example of such mechanistic confusion that can be found in the MS literature is on the important neurotransmitter acetylcholine $(\mathrm{ACh})$, which has been widely studied over several decades using various MS-based approaches [2-8]. ACh fragments to give two main products: an ion at $m / z$ 87, arising from loss of trimethylamine, and formation of trimethylammonium, $\mathrm{Me}_{3} \mathrm{NH}^{+}$. Surprisingly, there is no consensus on the mechanism for the loss of trimethylamine.

Unger et al. [2] and Ohashi et al. [3], who carried out early secondary ion mass spectrometry studies and

\footnotetext{
* This article is Part 63 of the series "Gas Phase Ion Chemistry of Biomolecules."

Address reprint requests to Prof. Richard A. J. O'Hair, University of Melbourne, School of Chemistry, Parkville, Victoria 3010, Australia. E-mail: rohair@unimelb.edu.au
}

Ishimaru et al. who carried out fast atom bombardment analysis [4], suggested that loss of trimethylamine occurs via the neighboring group mechanism [9] shown as path $\mathrm{A}$ in Scheme 1. In this case the carbonyl oxygen acts as a nucleophile, attacking the carbon adjacent to the trimethylammonium-leaving group, triggering trimethylamine loss to afford the cyclic, 2-methyl-1,3dioxolan-2-ylium ion, cation $\mathbf{A}$ [10]. Cation $\mathbf{A}$ is a resonance-stabilized ion that has been widely studied in both the condensed and gas phases. It is sufficiently stable to allow isolation as a salt and its X-ray crystal structure has been determined [10], together with its ${ }^{1} \mathrm{H}$ and ${ }^{13} \mathrm{C}$ NMR spectra [11]. In the gas phase, cation $\mathbf{A}$ is also readily formed by several different ion-molecule reactions of the acetyl cation with various neutral substrates, as shown in Scheme 2 [12-17]. Eberlin's group carried out ab initio calculations on $\mathbf{A}$ and its reactions in support of their experimental work and confirmed that it is a stable ion [13].

It is noteworthy that numerous studies have demonstrated that $\mathbf{A}$ and its related derivatives can also be formed in the condensed phase via cyclization of acylic precursors with suitable leaving groups [11, 18, 19]. In addition, neighboring group reactions have been proposed in the electron impact (EI)/MS of aliphatic esters
(C) 2009 Published by Elsevier Inc. on behalf of American Society for Mass Spectrometry. 1044-0305/09/\$32.00

doi:10.1016/j.jasms.2008.09.017
Published online September 25, 2008 Received August 11, 2008 Revised September 12, 2008 Accepted September 13, 2008 

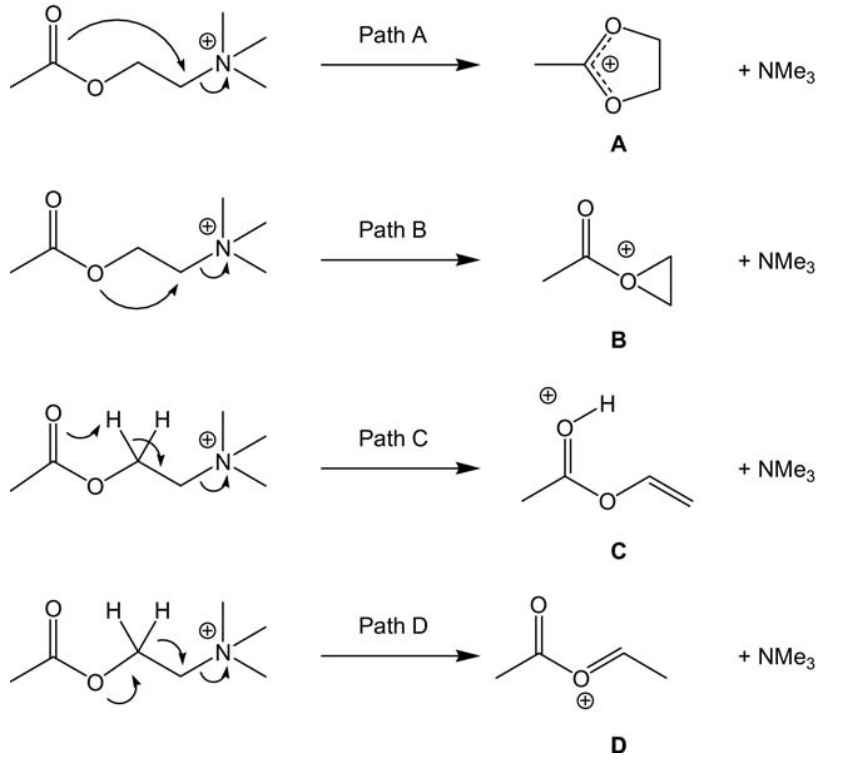

Scheme 1. Four potential mechanisms for loss of trimethylamine from acetylcholine. Paths A and B are neighboring group reactions, path $C$ is an intramolecular 1,2 elimination reaction, whereas path $\mathrm{D}$ is triggered by a 1,2 hydride shift.

to form ions related to structure $\mathbf{A}$ [19]. Importantly, in calculating the potential energy surface for $\mathrm{NH}_{3}$ loss from the addition of the acetyl cation to 2-aminoethanol (reaction 2 of Scheme 2, where $\mathrm{X}=\mathrm{NH}_{2}$ ), Moraes and Eberlin [16] determined that the final transition state (see TSf,d in Figure 9 of Moraes and Eberlin) is directly related to $\mathrm{Me}_{3} \mathrm{~N}$ loss from acetylcholine (compare reaction 2 of Scheme 2 with Path A of Scheme 1).

More recent studies, which examined the fragmentation of ACh using electrospray ionization tandem mass spectrometry (ESI/MS/MS), have inferred two other mechanisms based on different product ion structures. These involve: the ester oxygen acting as a neighboring nucleophile to yield the 1-methyl-oxiranium ion, B of Scheme 1 [5, 6, 8]; intramolecular proton transfer coupled with elimination of trimethylamine to provide 1-(vinyloxy)-ethanol-1-ium, C of Scheme 1 [7]. Thus it is worth considering both of these alternative product ion structures in more detail.

Cation $\mathbf{B}$ can be regarded as the product arising from attack of the acetyl cation onto the oxygen atom of the oxirane ring system (Scheme 2, reaction 3). In contrast to ion $\mathbf{A}$, we have not been able to find any reports on the isolation of stable salts of $\mathbf{B}$. Moraes and Eberlin have shown that $\mathbf{B}$ can be formed in a gas-phase ion-molecule reaction between the acetyl cation and oxiran, but that it undergoes a Meerwein rearrangement reaction to form the more stable A (Scheme 2) [16]. Using ab initio calculations, they showed that $\mathbf{A}$ is more stable than B by some $42.8 \mathrm{kcal} \mathrm{mol}^{-1}$ [at the MP2/6$311 \mathrm{G}(d, p) / / \mathrm{HF} / 6-311 \mathrm{G}(d, p)$ level of theory]. Thus apparently even in the gas phase, $\mathbf{B}$ may be unstable with respect to rearrangement to $\mathbf{A}$.
Cation $\mathrm{C}$ is the $\mathrm{C}=\mathrm{O}$ protonated form of vinylacetate. This structure has previously been proposed as the protonated form of vinylacetate in ion-molecule reactions involving dimethylether [20]. We have been unable to find any further references to this ion. However, in a study of the dimerization of vinylacetate, a tautomer in which protonation occurs on the terminal ethylene carbon rather than the carbonyl oxygen, was considered (D, Scheme 1) [21]. This has led us to consider a fourth potential mechanism for the elimination of trimethylamine, which proceeds with a 1,2hydride shift (Path D, Scheme 1).

Given the mechanistic ambiguity surrounding the fragmentation of acetylcholine, a detailed examination of the potential energy surface (PES) of ACh relevant to the four mechanisms described in Scheme 1 is presented here. In addition, the results of collision-induced dissociation (CID) experiments on deuterium labeled $\mathrm{ACh}$, which provide insight into the mechanism by which protonated trimethylamine is formed, are described.

\section{Experimental}

\section{Materials}

All purchased materials were used without further purification: acetylcholine chloride was from Fluka (Sydney, Australia); 2-bromoethanol (95\%) was from Sigma-Aldrich (Sydney, Australia); acetic- $d_{3}$-acid- $d$ (99.5 atom \% deuterium) was from Cambridge Isotope Laboratories (Andover, MA, USA); and the trimethylamine solution ( $45 \%$ in water) was from Merck-Schuchardt (Hohenbrunn, Germany).

\section{Synthesis of Acetyl-d -choline Bromide}

Preparation of acetyl- $d_{3}$-choline was achieved by following the procedure described by Hogg and Schowen
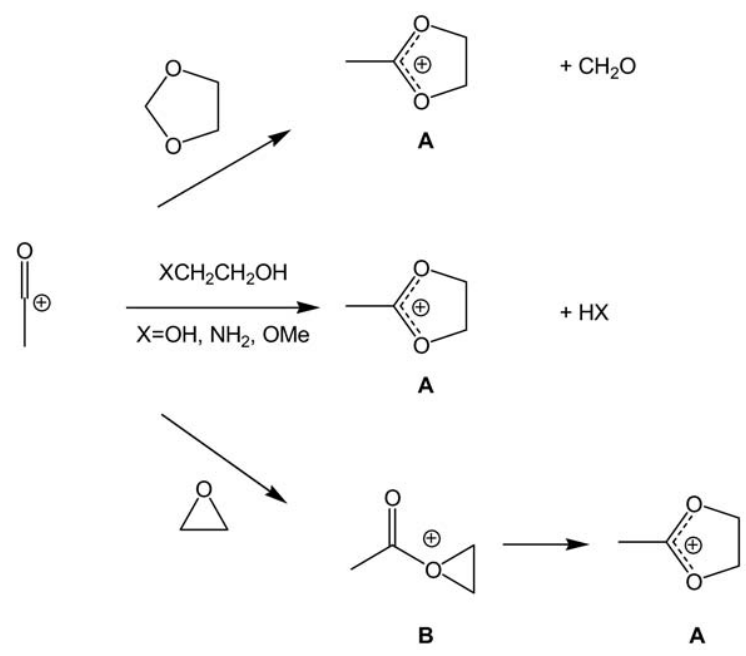

Scheme 2. Ion-molecule reactions of the acetyl cation with a range of neutral substrates that give rise to cations with structures $\mathbf{A}$ and $\mathbf{B}$. 
[22]. Briefly, acetic- $d_{3}$-acid- $d(99.5 \% d, 2.5 \mathrm{~g}, 39 \mathrm{mmol})$, 2-bromoethanol (4.9 g, $39 \mathrm{mmol})$, and $p$-toluenesulfonic acid monohydrate $(0.15 \mathrm{~g}, 0.7 \mathrm{mmol})$ were dissolved in toluene $(2.5 \mathrm{~mL})$. The resulting solution was refluxed on a Dean-Stark apparatus for $5 \mathrm{~h}$, during which about 0.8 $\mathrm{mL}$ of water was collected. The resulting 2-bromoethyl acetate- $d_{3}$ was purified by fractional distillation (collecting fractions above $150{ }^{\circ} \mathrm{C}$ ) to provide a yield of $5.31 \mathrm{~g}$ of 2-bromoethyl acetate- $d_{3}$ (b.p. $=160{ }^{\circ} \mathrm{C}$ ). The freshly prepared 2-bromoethyl acetate $(0.9 \mathrm{~g})$ was redissolved in toluene $(5.0 \mathrm{~mL})$ to which trimethylamine solution $(45 \%$ in water; $3.08 \mathrm{~g})$ was added in a precooled pressure tube. The tube was then sealed and heated to $90{ }^{\circ} \mathrm{C}$ with stirring for $5 \mathrm{~h}$. The tube was allowed to cool to room temperature followed by further cooling in an ice-salt bath before opening. The solvent was removed under vacuum to yield crystals of acetyl- $d_{3}$-choline bromide, which were subjected to MS analysis.

\section{Mass Spectrometry Experiments}

All experiments were carried out using a commercial linear ion trap mass spectrometer equipped with ESI (Thermo-Scientific LTQ-FT, San Jose, CA, USA). The samples, which were prepared in 50:50 methanol:water, were introduced to the mass spectrometer at a flow rate of $3 \mu \mathrm{L} / \mathrm{min}$. The sheath gas, capillary voltage, and temperature were adjusted to about 10 arbitrary units, $3.0 \mathrm{kV}$, and $250{ }^{\circ} \mathrm{C}$, respectively. The CID experiments were performed using standard procedures by mass selecting the desired precursor ion, with an activation window of $m / z 2$, and then subjecting it to CID using normalized collision energy of $29 \%$ and an activation Q of 0.25 for a period of $30 \mathrm{~ms}$.

\section{Theoretical Methods}

Geometry optimizations and electronic energy calculations were performed using the Gaussian 03 molecular modeling package [23]. Candidate starting structures for the determination of the global minimum were generated using Chem3D Pro. Structures of minima and transition states were optimized at the B3-LYP level of theory with the $6-31+\mathrm{G}(d, p)$ basis set. All optimized structures were subjected to vibrational frequency analysis to ensure they corresponded to either true minima (no imaginary frequencies) or transition states (1 imaginary frequency). Intrinsic reaction coordinate (IRC) runs were performed on each transition state, followed by geometry optimizations to ensure that they connected to the appropriate reactant and product ion minima. All optimized structures were then subjected to single-point energy calculations at the MP2/6$311++\mathrm{G}(2 d, p)$ level of theory and the final energies used to calculate the potential energy surfaces were corrected with the B3-LYP/6-31+G $(d, p)$ zero-point vibrational energies $\left(E_{\text {reported }}=E_{\text {electronic }}+E_{\text {zpve }}\right)$.

\section{Strategies for Calculating the Global} Minimum of $A C h$

High-energy conformers of acetylcholine (4000 structures) were initially generated using the MM2 molecular mechanics of the Chem3D Pro program. The parameters used for the molecular mechanics calculations were: step interval $=2.0 \mathrm{fs}$, frame interval $=10.0 \mathrm{fs}$, number of steps $=3000$, heating $/$ cooling rate $=1.0 \mathrm{kcal}$ $\mathrm{mol}^{-1} \mathrm{ps}^{-1}$, target temperature $=400 \mathrm{~K}$. One hundred of these high-energy structures were randomly selected for structure optimization at the PM3 level of theory and the B3-LYP/6-31G $(d)$ single-point energy calculated. The 15 most stable structures were further optimized at the B3-LYP/6-31+G $(d, p)$ level of theory and further subjected to MP2/6-311++G(2d,p) single-point energy calculations.

Several additional candidate structures were constructed manually ranging from an extended conformation, which minimizes any steric interaction, to closed conformations, which maximize ionic hydrogen bond interactions. These structures were optimized at the B3-LYP / 6-31+G $(d, p)$ and subjected to single-point energy calculations at the MP2/6-311++G(2d,p) level.

\section{Results and Discussion}

\section{DFT Calculations on the Conformations of Acetylcholine}

Using the approach described in the previous section, we found five low-energy minima, ACh01-ACh05, on the B3-LYP/6-31+G $(d, p)$ PES of acetylcholine. ${ }^{1}$ All structures ACh01-ACh05 have the trans-carbonyl arrangement and ACh01-ACh04 are stabilized by multiple ionic hydrogen bonds of the unconventional type $\mathrm{O} \cdots \mathrm{H}-\mathrm{C}$, in which the carbon is next to a positively charged nitrogen, ${ }^{2}$ whereas the higher-energy ACh05 has an extended structure. In addition, two isomers having cis-carbonyl arrangement were located at higher energies (see structures ACh06 and ACh07 in Supplementary Figure S2, which can be found in the electronic version of this article). Structures ACh01-ACh05 closely correspond to five low-energy structures (differing by only $4.5 \mathrm{kcal} \mathrm{mol}^{-1}$ ) identified by Deakyne and Meot-Ner on the HF/6-31G(d) PES [24]. Similarly, Seydou et al. [25] also reported five low-energy conformers at the B3PW91/6-311++G(d,p) level of theory, which closely correspond to ACh01-ACh05. Indeed reoptimization of these structures at the B3-LYP/6-311+G $(d, p)$ level of theory affords ACh01-ACh05 (data not shown). Muñoz-Caro et al. [26] examined the MP2/cc-pVDZ PES by systematically scanning the N7-C6-C5-O4 and C6-C5-O4-C2 dihedral angles (see Figure 1 for atom

\footnotetext{
${ }^{1}$ It should be noted that because an extended structure of ACh possesses a plane of symmetry, each conformer shown in Figure 1 is accompanied by its corresponding enantiomeric partner with the same relative energy (see Supplementary Figure S1).

2 This type of unconventional hydrogen bond has previously been reviewed and shall henceforth be referred to as ionic hydrogen [28].
} 

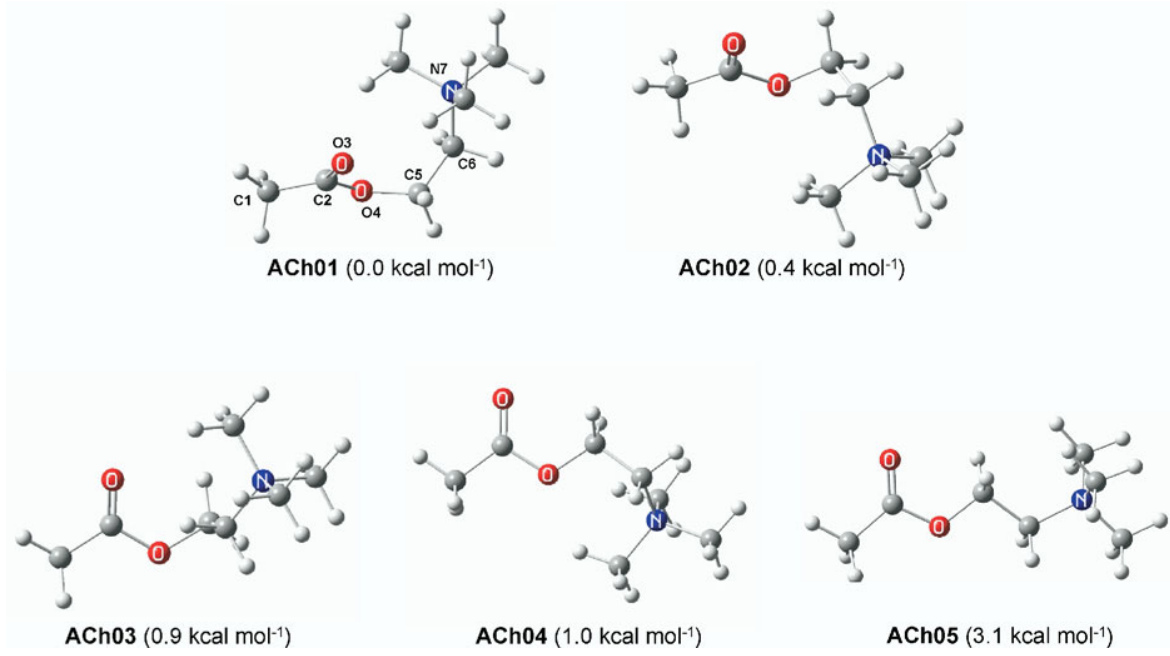

Figure 1. Density functional theory (DFT) calculated structures and relative energy of the lowest energy conformers of acetylcholine. The structures were optimized at the B3-LYP/6-31+G $(d, p)$ level of theory and the relative energies were calculated at the MP2/6-311++G(2d,p)//B3-LYP/6-31+G $(d, p)$ level of theory. Structure ACh01 is the lowest energy conformer of acetylcholine (global minima).

numbering), and located four minima. Although limited structural parameters were reported, these structures appear to correspond to ACh01, ACh02, ACh04, and ACh05. A recent B3-LYP/6-31G $(d, p)$ study by Kim et al. [27], carried out to complement their ion mobility studies of tertiary amines and quaternary ammonium cations, found a global minimum that closely resembles ACh01.

At the MP2/6-311++G $(2 d, p) / / \mathrm{B} 3-\mathrm{LYP} / 6-31+\mathrm{G}(d, p)$ level of theory ACh01 is the global minimum and, except for ACh05, all conformers differ by only $1.0 \mathrm{kcal}$ $\mathrm{mol}^{-1}$ from the global minimum. Structure ACh01 is stabilized by two ionic hydrogen bonds between the carbonyl and trimethylammonium moiety. The lowenergy conformers, ACh02-ACh04, differ primarily in the N7-C6-C5-O4 and the C6-C5-O4-C2 dihedrals and the number of ionic hydrogen bonds. As subsequently discussed in the following text, some of these conformers provide the reactive geometry to fragmentation of ACh. Structure ACh05 is the least stable of the five conformers (relative energy $=+3.1 \mathrm{kcal} \mathrm{mol}^{-1}$ ). It adopts an extended conformation and has no hydrogen bond interaction between the acetyl and trimethylammonium moiety. Seydou et al. [25] reported that significant barriers (up to $7.6 \mathrm{kcal} \mathrm{mol}^{-1}$ ) may exist for interconversion between the different conformers. However, barriers of this magnitude are significantly lower than the barriers associated with trimethylamine loss (see following text) and, given that low-energy CID is a relatively slow heating process (millisecond timescale [29]), all of these conformers should be accessible during ion activation by CID.

\section{DFT Calculations of Structures and Relative Energies of the Product Ions $A, B, C$, and D}

Structures of the four product ions, A-D, optimized at the B3-LYP/6-31+G $(d, p)$ level of theory are shown in
Figure 2, together with their relative MP2/6-311++G(2d,p) energies. The product arising from path $A$ is the most stable isomer with the charge being delocalized at the dioxolane moiety. In contrast, the three-membered ring ion $\mathbf{B}$ is the least stable isomer $\left(+34.3 \mathrm{kcal} \mathrm{mol}^{-1}\right)$. The comparatively high energy of cation $\mathbf{B}$ may be attributed to a combination of the inability of the acetyl group to delocalize the positive charge and the highly strained oxiranium ring. Indeed $\mathbf{B}$ is likely to be unstable with respect to either: isomerization to $\mathbf{A}$ by a Meerwein rearrangement, consistent with theoretical studies by Eberlin et al. [16] or, alternatively, further fragmentation to an acylium ion via elimination of oxirane. Indeed the $\mathrm{C}-\mathrm{O}$ bond length of structure $\mathbf{B}$ in Figure 2 is significantly elongated at $1.66 \AA$.

Structures $\mathbf{C}$ and $\mathbf{D}$ are open chain isomers, derived from protonation of vinylacetate at different sites. Con-

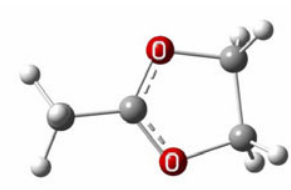

Structure $\mathbf{A}\left(0.0 \mathrm{kcal} \mathrm{mol}^{-1}\right)$

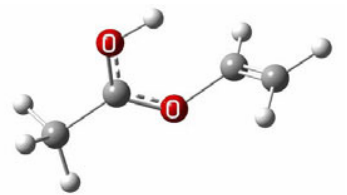

Structure C $\left(15.4 \mathrm{kcal} \mathrm{mol}^{-1}\right)$

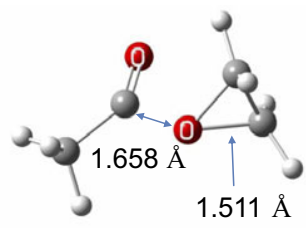

Structure B (34.3 kcal mol-1)

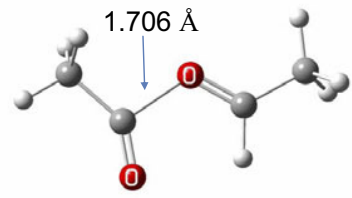

Structure D $\left(5.4 \mathrm{kcal} \mathrm{mol}^{-1}\right)$
Figure 2. DFT calculated structures and relative energy of the possible product ion structures $\mathbf{A}, \mathbf{B}, \mathbf{C}$, and $\mathbf{D}$. The relative energy was calculated at the MP2/6-311++G(2d,p)//B3-LYP/6-31+G $(d, p)$ level of theory. Structure $\mathbf{A}$ is the most stable product ion structure. 
sistent with previous reports, which considered the $\mathrm{CH}_{2}$ moiety as the preferred site of protonation [21] (structure D), we find that $\mathbf{D}$ is more stable $\left(+5.4 \mathrm{kcal} \mathrm{mol}^{-1}\right.$ relative to $\mathbf{A}$ ), in which protonation occurs on the carbonyl oxygen. However, the significantly elongated $\mathrm{C}$ - O bond length in $\mathbf{D}(1.71 \AA)$ indicates that it is may not be stable with respect to loss of acetaldehyde to afford the corresponding acylium ion.

\section{DFT Calculations of the Competing Fragmentation Pathways of Acetylcholine}

Although the DFT calculations of the structures A, B, C, and $\mathbf{D}$ predict that ion $\mathbf{A}$ is the thermodynamically favored product of $\mathrm{Me}_{3} \mathrm{~N}$ loss from acetylcholine, these provide no insights into whether this is also the kinetically favored product. Thus we have carried out DFT calculations on all species associated with the potential energy surfaces of the competing mechanisms shown in Scheme 1 and these are now described individually in detail.

(1) Fragmentation of ACh via neighboring group attack by $C=O$ group (Path $A$ ). Figure 3 shows the potential energy surface of fragmentation of $\mathrm{ACh}$ via neighboring group attack by the carbonyl oxygen at the carbon adjacent to the ammonium, Path A. Fragmentation proceeds via the low-energy conformer ACh03, through transition state A (TSA), to afford an ion-molecule complex (IMC) between $\mathbf{A}$ and $\mathrm{Me}_{3} \mathrm{~N}$. The barrier associated with formation of the IMC is $37.7 \mathrm{kcal} \mathrm{mol}^{-1}$ and its formation is endothermic by $31.0 \mathrm{kcal} \mathrm{mol}^{-1}$ relative to ACh01. Dissociation of the IMC to afford A and $\mathrm{Me}_{3} \mathrm{~N}$ is $44.8 \mathrm{kcal} \mathrm{mol}^{-1}$ endothermic relative to
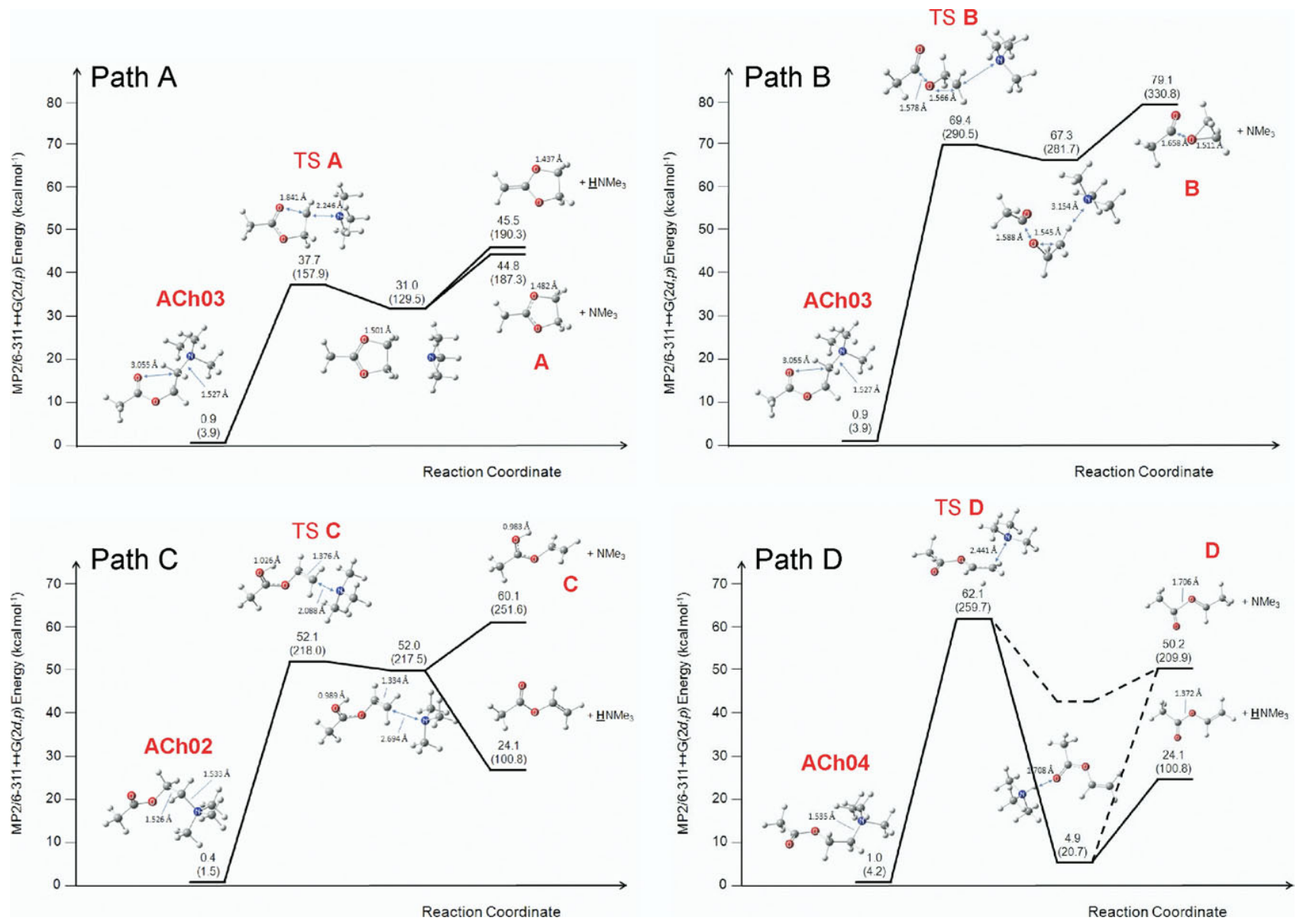

Figure 3. DFT potential energy surfaces of different pathways for fragmentation of acetylcholine. Path $\mathrm{A}$ is the neighboring group attack by the acetyl group to form a five-membered ring product ion $\mathrm{A}$ and loss of $\mathrm{Me}_{3} \mathrm{~N}$. Proton transfer within the ion-molecule complex forms the corresponding protonated $\mathrm{Me}_{3} \mathrm{~N}$ and a neutral five-membered ring. Path $\mathrm{B}$ is the neighboring group attack to form a three-membered ring product ion $\mathbf{B}$ with loss of $\mathrm{Me}_{3} \mathrm{~N}$. Path $\mathrm{C}$ is the elimination pathway to form an alkene product ion $\mathrm{C}$ and elimination of $\mathrm{Me}_{3} \mathrm{~N}$. Proton transfer process within the ion-molecule complex forms the corresponding protonated $\mathrm{Me}_{3} \mathrm{~N}$ and neutral vinylacetate. Path $\mathrm{D}$ is the 1,2hydride shift process that loses $\mathrm{Me}_{3} \mathrm{~N}$ and forms product ion $\mathrm{D}$. All structures were optimized at the B3-LYP/6-31+G $(d, p)$ level of theory and the relative energies were calculated at the MP2/6$311++\mathrm{G}(2 d, p) / / \mathrm{B} 3-\mathrm{LYP} / 6-31+\mathrm{G}(d, p)$ level of theory in $\mathrm{kcal} \mathrm{mol}^{-1}$. Energy values in parentheses are in $\mathrm{kJ} \mathrm{mol}^{-1}$. 
ACh01. Alternatively, proton transfer from the cation A to $\mathrm{Me}_{3} \mathrm{~N}$ may precede the separation of the IMC, which then results in the formation of the trimethylammonium ion, a product ion observed in the CID spectrum of ACh. Intermolecular proton transfer within ionmolecule complexes is a common and important process during the fragmentation of protonated amino acids and peptides, which has been proposed to occur with a negligible energy barrier depending on the relative proton affinity (PA) of the individual neutral species [30]. In the present example, transfer of a proton from the exocyclic $-\mathrm{CH}_{3}$ group to trimethylamine followed by dissociation is only marginally more endothermic $\left(0.7 \mathrm{kcal} \mathrm{mol}^{-1}\right)$ than dissociation without proton transfer.

(2) Fragmentation of ACh via neighboring group attack by ester $O$ (Path $B)$. The PES associated with neighboring group attack by the ester $\mathrm{O}$ of the carbon adjacent to the trimethylammonium (Path B) is also shown in Figure 3. This mechanism proceeds via a considerably higher barrier, $69.4 \mathrm{kcal} \mathrm{mol}^{-1}$, than was the case for path A. The resulting ion-molecule complex between $\mathbf{B}$ and $\mathrm{Me}_{3} \mathrm{~N}$ is only marginally more stable $\left(67.3 \mathrm{kcal} \mathrm{mol}^{-1}\right)$ and dissociation of the complex to form $\mathbf{B}$ and $\mathrm{Me}_{3} \mathrm{~N}$ is endothermic by $79.1 \mathrm{kcal} \mathrm{mol}^{-1}$. Note that the $\mathrm{C}-\mathrm{O}$ bond length increases from the transition state to the IMC (1.566 to $1.588 \AA$ ). As previously discussed, the product ion $\mathbf{B}$ has even longer $\mathrm{C}-\mathrm{O}$ bond length (1.658 A) and distorted carbonyl bond angle.

(3) Fragmentation of ACh via elimination mechanism (Path C). As summarized in Scheme 1, Path $C$ is an intramolecular elimination process that forms $\mathrm{C}=\mathrm{O}$ protonated vinylacetate and can proceed via either anti or syn elimination. The DFT calculated potential energy surface in Figure 3 is associated with the anti-elimination mechanism whereby the proton and trimethylamine are in the anti arrangement. The potential energy surface of the syn-elimination mechanism, which is calculated to proceed via a higher energy transition state and which yields $\mathrm{Me}_{3} \mathrm{NH}^{+}$and vinylacetate as the products, is given in Supplementary Figure S3. The transition energy associated with the anti-elimination reaction is $+52.1 \mathrm{kcal} \mathrm{mol}^{-1}$, whereas the resulting ion-molecule complex is only marginally more stable, indicating the reverse reaction is almost barrierless. Overall, the elimination of $\mathrm{Me}_{3} \mathrm{~N}$ is $60.1 \mathrm{kcal} \mathrm{mol}^{-1}$ endothermic. Proton transfer, from $\mathrm{C}$ to $\mathrm{Me}_{3} \mathrm{~N}$ in the intermediate IMC before separation yields a substantially more stable pair of products in protonated trimethylamine and vinylacetate. Indeed, this reaction is endothermic by $24.1 \mathrm{kcal}$ $\mathrm{mol}^{-1}$, making it thermodynamically preferred over all the reactions discussed earlier. This observation can be explained by the higher proton affinity of $\mathrm{Me}_{3} \mathrm{~N}$ compared to vinylacetate $[\mathrm{PA}($ trimethylamine $)=226.8 \mathrm{kcal}$ $\mathrm{mol}^{-1}$ versus PA(vinylacetate $)=194.5 \mathrm{kcal} \mathrm{mol}^{-1}$ ] [31].
(4) Fragmentation of ACh via 1,2-hydride migration mechanism (Path D). Dissociation via path $\mathrm{D}$ is induced by a 1,2-hydride migration to form the $\mathrm{CH}_{2}$-protonated vinylacetate product ion $\mathbf{D}$ and trimethylamine. Figure 3 (Path D) summarizes the DFT calculated potential energy surface of this pathway. This process has a transitionstate energy of $+62.1 \mathrm{kcal} \mathrm{mol}^{-1}$. The energy of the separated product ion $\mathbf{D}$ and $\mathrm{Me}_{3} \mathrm{~N}$ is lower than the transition-state energy (+50.2 $\left.\mathrm{kcal} \mathrm{mol}^{-1}\right)$, presumably attributed to the preference to protonation at the $\mathrm{CH}_{2}$ group of vinylacetate. Several attempts to locate the intermediate IMC between $\mathbf{D}$ and trimethylamine were unsuccessful, with all optimizations instead leading to an IMC in which a proton had been transferred to the trimethylamine. Failure to observe the IMC between $\mathbf{D}$ and $\mathrm{NMe}_{3}$ suggests that it is unstable with respect to intermolecular proton transfer from $\mathbf{D}$ to $\mathrm{NMe}_{3}$. The IMC formed between $\mathrm{Me}_{3} \mathrm{NH}^{+}$and vinylacetate is substantially more stable $\left(+4.9 \mathrm{kcal} \mathrm{mol}^{-1}\right)$ than the other IMCs discussed earlier. Dissociation of this IMC to yield protonated trimethylamine and neutral vinylacetate is endothermic by $24.1 \mathrm{kcal} \mathrm{mol}^{-1}$, considerably less endothermic than loss of $\mathrm{NMe}_{3}$, to afford product $\mathbf{D}$ $\left(+50.2 \mathrm{kcal} \mathrm{mol}^{-1}\right)$, consistent with the higher proton affinity of $\mathrm{Me}_{3} \mathrm{~N}$ [31].

(5) Possibility of isomerization during fragmentation of $A C h$. Of the four possible fragmentation pathways, Path A, the neighboring group mechanism, is the kinetically favored pathway (transition-state energy $=+37.7$ $\mathrm{kcal} \mathrm{mol}^{-1}$ ). Furthermore, since $\mathbf{A}$ is the lowest-energy $\mathrm{C}_{4} \mathrm{H}_{7} \mathrm{O}_{2}{ }^{+}$isomer (see Figure 2), Path $\mathrm{A}$ is the thermodynamically preferred pathway for $\mathrm{Me}_{3} \mathrm{~N}$ loss (overall energy requirement for this path $=+44.8 \mathrm{kcal} \mathrm{mol}^{-1}$ ). However, a comparison of all four of the potential energy surfaces reveals that the exit channel to form $\mathbf{A}$ and $\mathrm{Me}_{3} \mathrm{~N}$ does not represent the formation of the thermodynamically favored pair of products, which instead corresponds to the formation of $\mathrm{Me}_{3} \mathrm{NH}^{+}$and vinylacetate. Since protonated trimethylamine is also a product in the CID spectrum of ACh, an important question that arises is "Can the thermodynamic product be formed from the kinetically preferred pathway (Path A)?" Earlier, in the introductory section, proton transfer within the ion-molecule complex was considered to arise from loss of the proton from the exocyclic $\mathrm{CH}_{3}$ group, as shown in path (a) of Scheme 3. However, proton transfer could occur from the ring methylene groups with concomitant ring opening, which would provide a route to protonated trimethylamine and vinylacetate, the thermodynamically favored products [as shown in path (e) of Scheme 3]. Therefore we have calculated the isomerization process that connects TSA and the thermodynamic product $\left(\mathrm{Me}_{3} \mathrm{NH}^{+}\right.$and vinylacetate), Path E. Figure 4 summarizes the potential energy surface for this process. The transition state for this isomerization process involves a concerted ring opening of the five-membered ring to form the thermodynamic product. This process has a transition-state 
<smiles>CC1=[O+]CC(C)(N(C)C)CO1</smiles>

$\mathrm{ACh}$
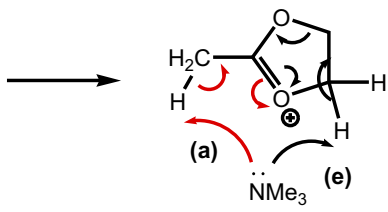

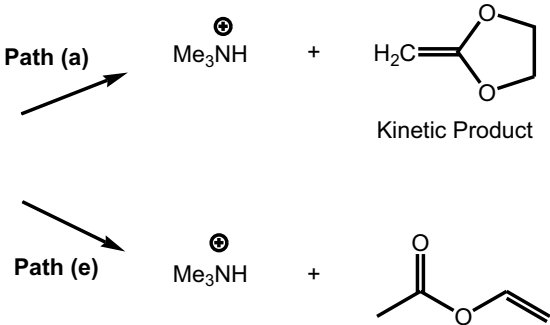

Thermodynamic Product

Scheme 3. Competing ways of forming protonated trimethylamine via the neighboring group pathway ion-molecule complex intermediate: Path a involves removal of a proton from the exocylic methyl group, giving rise to the kinetic neutral product; path e involves proton transfer from the methylene ring carbon, which triggers ring opening to form the thermodynamic neutral product.

energy of $+51.0 \mathrm{kcal} \mathrm{mol}^{-1}$. Since the barrier for this process is significantly above the dissociation threshold for loss of $\mathrm{Me}_{3} \mathrm{~N}$ or formation of $\mathrm{Me}_{3} \mathrm{NH}^{+}$via abstraction of a proton from the exocyclic carbon (Path A), it seems an unlikely process under low-energy CID conditions.

\section{Discussions on the Overall Fragmentation Mechanism of Acetylcholine}

Several important points arise from a consideration of the competing mechanisms for fragmentation of acetylcholine. First, the global minimum is not the reactive conformer in all dissociation processes calculated. Second, the neighboring group attack mechanism by the $\mathrm{C}=\mathrm{O}$ moiety to form a five-membered product ion $\mathrm{A}$ and its complementary exit channel (Path A) is the kinetically favored pathway with a transition-state en- ergy of $+37.7 \mathrm{kcal} \mathrm{mol}^{-1}$. The overall energy barrier for the formation of product ion $\mathbf{A}$ is $+44.8 \mathrm{kcal} \mathrm{mol}^{-1}$ and that for the formation of the complementary $\mathrm{Me}_{3} \mathrm{NH}^{+}$ cation is $+45.5 \mathrm{kcal} \mathrm{mol}^{-1}$. Path B, in which ACh fragments via neighboring group attack by the ester moiety to form a three-membered ring product ion, has an overall energy requirement of $+79.1 \mathrm{kcal} \mathrm{mol}^{-1}$. Thus fragmentation of $\mathrm{ACh}$ is unlikely to occur via this pathway. Third, the thermodynamically favored set of products, $\mathrm{Me}_{3} \mathrm{NH}^{+}$and neutral vinylacetate, can be formed via three possible pathways: (1) isomerization within cation $\mathrm{A}-\mathrm{Me}_{3} \mathrm{~N}$ complex [Scheme 3 path (e) and Figure 4] via TSE (transition-state energy $=+51.0 \mathrm{kcal}$ $\left.\mathrm{mol}^{-1}\right)$; (2) the elimination process shown in Path C (TSE $=+52.1 \mathrm{kcal} \mathrm{mol}^{-1}$ ); and (3) the 1,2-hydride migration process shown in Path D (TSE $=+62.1 \mathrm{kcal}$ $\mathrm{mol}^{-1}$ ). All of these three pathways have higher energy requirements than Path A and are thus unlikely to be

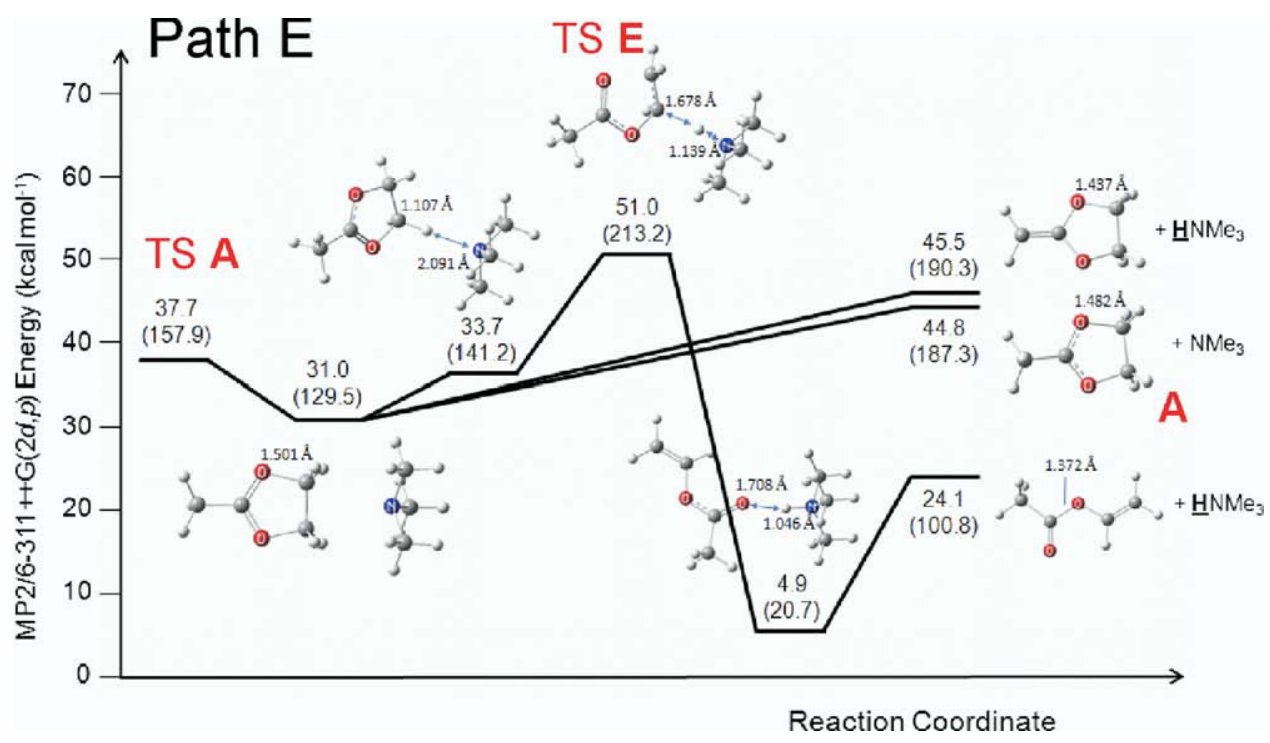

Figure 4. DFT potential energy surfaces of different pathways for fragmentation of acetylcholine. Path $\mathrm{E}$ is the proton transfer path that connects the kinetically preferred pathway (Path A) to the thermodynamically preferred products, $\mathrm{Me}_{3} \mathrm{NH}^{+}$and neutral vinylacetate. All structures were optimized at the B3-LYP/6-31+G $(d, p)$ level of theory and the relative energy was calculated at the $\mathrm{MP} 2 / 6-311++\mathrm{G}(2 d, p) / / \mathrm{B} 3-\mathrm{LYP} / 6-31+\mathrm{G}(d, p)$ level of theory in $\mathrm{kcal} \mathrm{mol}^{-1}$. Energy values in parentheses are in $\mathrm{kJ} \mathrm{mol}^{-1}$. 
accessed under low-energy CID conditions. Thus Path $\mathrm{A}$ is predicted by theory to be the preferred mechanism for the formation of both fragment ions (product ion A and $\mathrm{Me}_{3} \mathrm{NH}^{+}$) under low-energy CID conditions.

\section{Comparison of Theoretical Calculations of the Fragmentation of ACh with Tandem Mass Spectrometry and Deuterium Labeling Experiments}

To confirm the origins of protonated trimethylamine, we performed low-energy CID experiments on ESIgenerated ACh using a linear ion trap. The resultant spectrum is illustrated in Figure 5a and, consistent with previous work, shows a dominant loss of $\mathrm{Me}_{3} \mathrm{~N}$ together with the formation of protonated trimethylamine. Our calculations suggest that the kinetically preferred pathway for the loss of $\mathrm{Me}_{3} \mathrm{~N}$ is via Path A of Scheme 1 and thus ion $m / z 87$ can be assigned as the five-membered product ion A. Since the calculations suggest several different pathways to form protonated trimethylamine $(m / z 60)$, we have synthesized acetyl- $d_{3}-$ choline $\left(d_{3}-\mathrm{ACh}\right)$ in which all the hydrogen atoms of the acetyl group have been substituted by deuterium. The low-energy CID spectrum of $d_{3}$-ACh is shown in Figure $5 b$. The main ion at $m / z 90$ arises from the loss of $\mathrm{Me}_{3} \mathrm{~N}$ to form product ion $\mathbf{A}$, which contains three deuterium atoms. Importantly, the other product ion observed at $\mathrm{m} / \mathrm{z} 61$ corresponds to deuteronated trimethylamine, $\mathrm{Me}_{3} \mathrm{ND}^{+}$. The exclusive formation of the $m / z 61$ ion provides convincing evidence that $\mathrm{Me}_{3} \mathrm{NH}^{+}$is the kinetic product, formed via proton transfer from the $\mathrm{CH}_{3}$ group [path (a) of Scheme 3], thereby providing support that fragmentation of ACh occurs via Path A (Scheme 1).
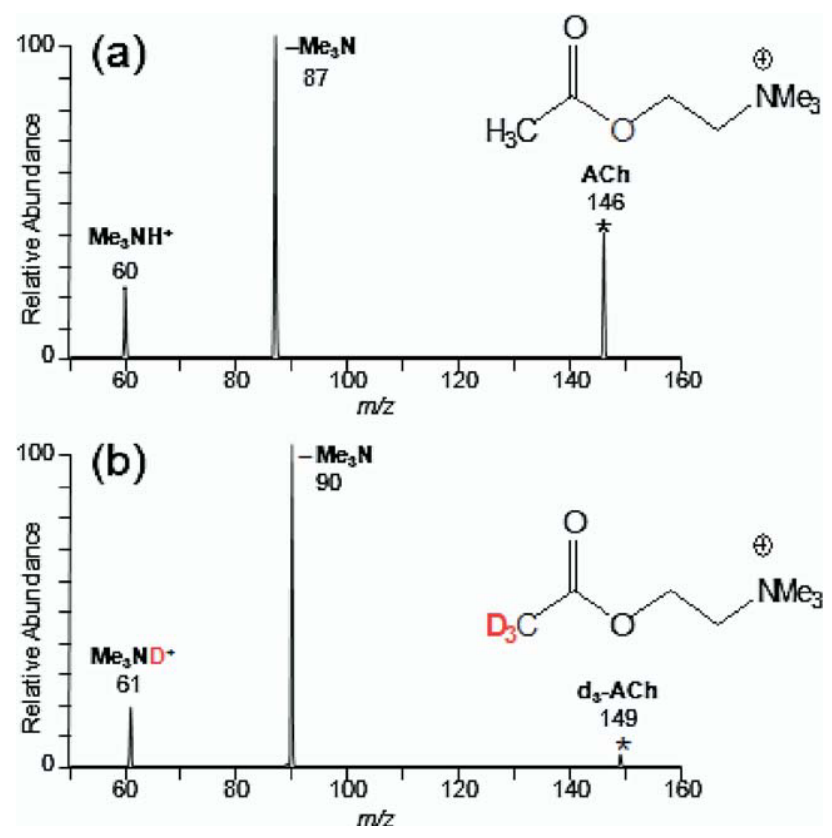

Figure 5. Low-energy CID spectra of (a) acetylcholine and (b) acetyl- $d_{3}$-choline. Precursor ions were formed via ESI and CID was carried out in an LTQ-FT linear ion-trap mass spectrometer.

\section{Conclusions}

Based on the combination of DFT calculations and isotopic labeling experiments conducted here, we conclude that acetylcholine undergoes the loss of trimethylamine via a neighboring group mechanism to form the cyclic, 2-methyl-1,3-dioxolan-2-ylium ion (structure A). Furthermore, formation of protonated trimethylamine involves the abstraction of a proton from the exocyclic- $\mathrm{CH}_{3}$ group of the 2-methyl-1,3-dioxolan-2ylium ion in the intermediate IMC formed following neighboring group attack. The presence of both product ions may be readily understood because of the similar endothermicity of both pathways. Although the neighboring group pathway is kinetically preferred, formation of protonated trimethylamine and neutral vinylacetate represents the thermodynamically preferred products, highlighting that kinetic products are formed under low-energy CID conditions.

Although the work described here highlights the benefits of using theoretical calculations and isotopic labeling to establish which competing mechanisms are most likely to operate under low-energy CID conditions, such detailed studies are clearly not appropriate for all analytical and bioanalytical publications that utilize tandem mass spectrometry. Nonetheless, it seems worth establishing what minimum standards are required for proposing structures of fragment ions and thus mechanisms for their formation. Boyd has noted that " 'fragmentation mechanisms,' involving hypothesized ion structures, must provide a level of experimental evidence that justifies the amount of speculative discussion" [1]. It could also be argued that an appreciation of the available "tools" and "concepts" that underpin the mechanisms of ion fragmentation [9] and an awareness of earlier literature are also paramount.

\section{Acknowledgments}

We thank the ARC for financial support via the ARC Centre of Excellence in Free Radical Chemistry and Biotechnology. The authors gratefully acknowledge the generous allocation of computing time from the Victorian Institute for Chemical Science High Performance Computing Facility.

\section{References}

1. Boyd, R. K. Editorial Changes to Instructions for Authors. Rapid Commun. Mass Spectrom. 2005, 19, 3419.

2. Unger, S. E.; Ryan, T. M.; Cooks, R. G. The Identification of Choline and Its Esters by Secondary Ion Mass Spectrometry. Surf. Interface Anal. 1981, 3, 12-15.

3. Ohashi, M.; Iino, T.; Takahashi, T.; Yoneda, M.; Kyushin, S.; Tsujimoto, K. Cluster Ions in the Secondary Ion Mass Spectrometry of Choline and Acetylcholine Halides. Org. Mass Spectrom. 1990, 25, 109-114.

4. Ishimaru, H.; Ikarashi, Y.; Yuji, M.; Weintraub, S. T. Continuous-Flow Fast Atom Bombardment Mass Spectrometry of Acetylcholine: Interpretation of Mass Spectral Fragmentation. J. Mass Spectrom. Soc. Jpn. 1995, 43, 19-26.

5. Dunphy, R.; Burinsky, D. J. Detection of Choline and Acetylcholine in a Pharmaceutical Preparation Using High-Performance Liquid Chromatography/Electrospray Ionization Mass Spectrometry. J. Pharm. Biomed. Anal. 2003, 31, 905-915.

6. Uutela, P.; Reinila, R.; Piepponen, P.; Ketola, R. A.; Kostiainen, R. Analysis of Acetylcholine and Choline in Microdialysis Samples by 
Liquid Chromatography/Tandem Mass Spectrometry. Rapid Commun. Mass Spectrom. 2005, 19, 2950-2956.

7. Zhang, M.-Y., Hughes, Z. A.; Kerns, E. H.; Lin, Q.; Beyer, C. E. Development of a Liquid Chromatography/Tandem Mass Spectrometry Method for the Quantitation of Acetylcholine and Related Neurotransmitters in Brain Microdialysis Samples. J. Pharm. Biomed. Anal. 2007, 44, 586-593.

8. Keski-Rahkonen, P.; Lehtonen, M.; Ihalainen, J.; Sarajarvi, T.; Auriola, S. Quantitative Determination of Acetylcholine in Microdialysis Samples Using Liquid Chromatography/Atmospheric Pressure Spray Ionization Mass Spectrometry. Rapid Commun. Mass Spectrom. 2007, 21, 2933-2943.

9. For a review highlighting the importance of neighboring group reactions in amino acid and peptide chemistry, see: O'Hair, R. A. J. The Role of Nucleophile-Electrophile Interactions in the Unimolecular and Bimolecular Gas Phase Ion Chemistry of Peptides and Related Systems. J. Mass Spectrom. 2000, 35, 1377-1381.

10. Paulsen, H.; Dammeyer, R. Carboxonium Compounds in Carbohydrate Chemistry, XXIX. Investigation of Charge Distribution in 1,3-Dioxolan2-ylium Ions. Chem. Ber. 1976, 109, 1837-1849.

11. Paulsen, H.; Dammeyer, R. Carboxonium Compounds in Carbohydrate Chemistry. 33. Proton and Carbon-13 NMR Studies of Charge Distribution in Substituted 1,3-Dioxan-2-ylium Salts. Org. Magn. Reson. 1979, 12, 616-623.

12. Eberlin, M. N.; Cooks, R. G. Gas-Phase Oxirane Addition to Acylium Ions on Reaction with 1,3-Dioxolanes Elucidated by Tandem and Triple Stage Mass Spectrometric Experiments. Org. Mass Spectrom. 1993, 28, $679-687$.

13. Moraes, L. A. B. Gozzo, F. C. Eberlin, M. N. Vainiotalo, P. Transacetalization with Acylium Ions. A Structurally Diagnostic Ion/Molecule Reaction for Cyclic Acetals and Ketals in the Gas Phase. J. Org. Chem. 1997, 62, 5096-5103

14. Moraes, L. A. B.; Pimpim, R. S.; Eberlin, M. N. Novel Ketalization Reaction of Acylium Ions with Diols and Analogues in the Gas Phase. J. Org. Chem. 1996, 61, 8726-8727.

15. Moraes, L. A. B.; Eberlin, M. N. Ketalization of Gaseous Acylium Ions. J. Am. Soc. Mass Spectrom. 2001, 12, 150-162.

16. Moraes, L. A. B.; Eberlin, M. N. The Gas-Phase Meerwein Reaction. Chem. Eur. J. 2000, 6, 897-905.

17. For a review on the earlier literature see: Perst, $\mathrm{H}$. Oxonium Ions in Organic Chemistry; Verlag Chemie/Academic Press: New York, 1971; pp $110-123$.

18. Wilen, S. H.; Delguzzo, L.; Saferstein, R. Experimental Evidence for AcO-7 Neighboring Group Participation. Tetrahedron 1987, 43, 50895094 .

19. Bauman, W. J.; Aasen, A. J.; Kramer, J. K. G.; Holman, R. T. Evidence for the Electron Impact Induced Formation of Prominent Cyclic Acetal Ions from Aliphatic Ester Lipids. J. Org. Chem. 1973, 38, 3767.
20. Kim, J. K.; Caserio, M. C. Acyl-Transfer Reactions in the Gas Phase. The Question of Tetrahedral Intermediates. J. Am. Chem. Soc. 1981, 103, 2124-2127.

21. Mora, M. A. A Molecular Orbital Study of the Dimerization Process of Vinyl Monomers. Int. J. Quantum Chem. 1997, 65, 767-785.

22. Hogg, J. L.; Schowen, R. L. Synthetic Procedures for Deuterium-Labeled Acetylcholine Perchlorates. J. Pharm. Sci. 1974, 63, 1620-1623.

23. Frisch, M. J.; Trucks, G. W.; Schlegel, H. B.; Scuseria, G. E.; Robb, M. A.; Cheeseman, J. R.; Montgomery, Jr., J. A.; Vreven, T.; Kudin, K. N.; Burant, J. C.; Millam, J. M.; Iyengar, S. S.; Tomasi, J.; Barone, V.; Mennucci, B.; Cossi, M.; Scalmani, G.; Rega, N.; Petersson, G. A.; Nakatsuji, H.; Hada, M.; Ehara, M.; Toyota, K.; Fukuda, R.; Hasegawa, J.; Ishida, M.; Nakajima, T.; Honda, Y.; Kitao, O.; Nakai, H.; Klene, M.; Li, X.; Knox, J. E.; Hratchian, H. P.; Cross, J. B.; Bakken, V.; Adamo, C.; Jaramillo, J.; Gomperts, R.; Stratmann, R. E.; Yazyev, O.; Austin, A. J.; Cammi, R.; Pomelli, C.; Ochterski, J. W.; Ayala, P. Y.; Morokuma, K.; Voth, G. A.; Salvador, P.; Dannenberg, J. J.; Zakrzewski, V. G.; Dapprich, S.; Daniels, A. D.; Strain, M. C.; Farkas, O.; Malick, D. K.; Rabuck, A. D.; Raghavachari, K.; Foresman, J. B.; Ortiz, J. V.; Cui, Q.; Baboul, A. G.; Clifford, S.; Cioslowski, J.; Stefanov, B. B.; Liu, G.; Liashenko, A.; Piskorz, P.; Komaromi, I.; Martin, R. L.; Fox, D. J.; Keith, T.; Al-Laham, M. A.; Peng, C. Y.; Nanayakkara, A.; Challacombe, M.; Gill, P. M. W. Johnson, B.; Chen, W.; Wong, M. W.; Gonzalez, C.; Pople, J. A. Gaussian 03, Revision C.02, Gaussian, Inc.: Wallingford CT, 2004.

24. Deakyne, C. A.; Meot-Ner, M. Ionic Hydrogen Bonds in Bioenergetics. 4. Interaction Energies of Acetylcholine with Aromatic and Polar Molecules. J. Am. Chem. Soc. 1999, 121, 1546-1557.

25. Seydou, M.; Grégoire, G.; Liquier, J.; Lemaire, J.; Schermann, J. P.; Desfrançois, C. Experimental Observation of the Transition between Gas-Phase and Aqueous Solution Structures for Acetylcholine, Nicotine, and Muscarine Ions. J. Am. Chem. Soc. 2008, 130, 4187-4195.

26. Muñoz-Caro, C.; Niño, A.; Mora, M.; Reyes, S.; Melendez, F. J.; Castro, M. E. Conformational Population Distribution of Acetylcholine, Nicotine and Muscarine in Vacuum and Solution. J. Mol. Struct. (Theochem.) 2005, 726, 115-124.

27. Kim, H.; Kim, H.; I., Johnson, P. V.; Beegle, L. W.; Beauchamp, J. L.; Goddard, W. A.; Kanik, I. Experimental and Theoretical Investigation into the Correlation between Mass and Ion Mobility for Choline and Other Ammonium Cations in $\mathrm{N}_{2}$. Anal. Chem. 2008, 80, 1928-1936.

28. Meot-Ner, M. The Ionic Hydrogen Bond. Chem. Rev. 2005, 105, 213-284.

29. McLuckey, S. A.; Goeringer, D. E. Slow Heating Methods in Tandem Mass Spectrometry. J. Mass Spectrom. 1997, 32, 461-474.

30. Paizs, B.; Suhai, S. Fragmentation Pathways of Protonated Peptides. Mass Spectrom. Rev. 2005, 24, 508-548.

31. Hunter, E. P.; Lias, S. G. Proton Affinity Evaluation. In NIST Chemistry WebBook (NIST Standard Reference Database Number 69), Linstrom, P. I.; Mallard, W. G., Eds.; National Institute of Standards and Technology (http://webbook.nist.gov): Gaithersburg, MD; June 2005. 